\title{
Fatal neonatal respiratory failure in an infant with congenital hypothyroidism due to haploinsufficiency of the NKX2-1 gene: alteration of pulmonary surfactant homeostasis
}

\author{
Barbara Kleinlein, ${ }^{1}$ Matthias Griese, ${ }^{2}$ Gerhard Liebisch, ${ }^{3}$ Heiko Krude, ${ }^{4}$ Peter Lohse, ${ }^{5}$ \\ Charalampos Aslanidis, ${ }^{3}$ Gerd Schmitz, ${ }^{3}$ Jochen Peters, ${ }^{1}$ Andreas Holzinger ${ }^{2}$
}

${ }^{1}$ Kinderklinik Dritter Orden

Munich, Germany

2Dr von Hauner Children's

Hospital, Ludwig-Maximilian

University, Munich, Germany

${ }^{3}$ Institute for Clinical Chemistry and Laboratory Medicine, University of Regensburg

Regensburg, Germany

${ }^{4}$ Institute of Experimental

Pediatric Endocrinology,

Charité - Universitätsmedizin

Berlin, Berlin, Germany

${ }^{5}$ Department of Clinical

Chemistry-Großhadern,

Ludwig-Maximilian University,

Munich, Germany

\section{Correspondence to}

Professor Andreas Holzinger, Dr von Hauner Children's

Hospital, Ludwig-Maximilian University Munich,

Lindwurmstrasse 4, Munich, 80337, Germany;

andreas.holzinger@med.unimuenchen.de

Accepted 18 April 2010 Published Online First

28 June 2010

\section{SUMMARY}

Defects of the NKX2-1 gene, encoding thyroid transcription factor-1, cause brain-thyroid-lung syndrome (MIM 610978), characterised by benign hereditary chorea, congenital hypothyroidism and respiratory disease. The case of a term infant with mild primary congenital hypothyroidism and neonatal persistent respiratory failure with fatal outcome at 10 months of age despite continuous ventilatory support is described. Congenital defects of genes known to disturb surfactant protein and lipid homeostasis (SFTPB, SFTPC, $A B C A 3)$ were excluded. Hypothyroidism prompted sequencing of NKX2-1, which revealed a heterozygous 29 bp deletion (c.278_306del29) disrupting the affected allele. Analysis of bronchoalveolar lavage fluid demonstrated an abnormally low amount of surfactant protein C (SP-C) in relation to SP-B, and low levels of surfactant phospholipids, indicating disturbance of SP and lipid homeostasis as a consequence of NKX2-1 haploinsufficiency. NKX2-1 haploinsufficiency may lead to lethal respiratory failure of the newborn due to disruption of pulmonary surfactant homeostasis. NKX2-1 gene analysis should be considered when investigating irreversible respiratory insufficiency of the newborn.

\section{INTRODUCTION}

Fatal respiratory failure in term newborns has been associated with genetic defects disrupting homeostasis of the pulmonary surfactant system, such as mutations in genes encoding surfactant protein $\mathrm{B}(\mathrm{SP}-\mathrm{B})^{1}$ or $\mathrm{SP}-\mathrm{C}^{2}$ or $A B C A 3$ encoding the lamellar body-associated $\mathrm{ABC}$ transporter $\mathrm{A} 3{ }^{3}$ Thyroid transcription factor-1 (TTF-1), encoded by the gene NKX2-1, has been established as being crucial for lung development and function. In NKX2-1 null mutant mice, development of the ventral forebrain, pituitary and thyroid is severely impaired, as is lung branching. ${ }^{4}$ Heterozygous NKX2-1 defects have been found in patients with benign hypothyroidism and pulmonary alterations ${ }^{5}$ or in combination with benign hereditary chorea. ${ }^{67}$ Therefore, the term 'brain-thyroid-lung syndrome' has been introduced. ${ }^{8}$ However, any one or even two of these manifestations may be missing. Of the 46 patients reported to date with clinical and molecular genetic information available, respiratory disease appears to be the most inconstant finding (54\% of patients identified). ${ }^{9}$ In a single patient with hypothyroidism and lethal neonatal respiratory failure, a functionally relevant missense mutation of NKX2-1 (I207F) was reported recently. However, the absence of mutations in genes previously known to be responsible for fatal neonatal respiratory failure such as SFTPB or SFTPC encoding the hydrophobic SP-B and SP-C or $A B C A 3$, was not demonstrated. ${ }^{10}$

Here we report the fatal outcome of a term male infant with mild hypothyroidism and respiratory failure requiring mechanical ventilatory support shortly after birth. We demonstrate the absence of defects in the SFTPB, SFTPC and ABCA3 genes. Instead, a heterozygous disrupting mutation in NKX2-1 was identified. A disturbance of pulmonary surfactant composition affecting proteins and lipids is reported.

\section{SUBJECT AND METHODS Case report}

After an uneventful pregnancy, a male infant was born spontaneously at 41 weeks of gestation to a healthy non-consanguineous Caucasian couple as their first child. Postnatal respiratory adaptation was normal, but tachypnea with mild intercostal inspiratory retractions and flaring nostrils was noted on day 3 of life, which prompted transfer to a newborn intensive care unit. On admission, oxygen saturation showed varying readings from $86 \%$ to $97 \%$ on room air, while respiratory rate was 100/min. Antibiotic treatment was begun. However, a bacterial, viral or parasitic infection was subsequently ruled out, as was a cardiac defect. Routine screening for metabolic diseases on day 4 of life detected an elevation of thyrotropin (thyroid-stimulating hormone (TSH); 48 $\mathrm{mU} / 1$; normal $<24)$, while free thyroxine was normal (fT4; 18.4 pmol/1; normal 11-22.3). Treatment with L-thyroxine was begun for congenital hypothyroidism. Since initial fT4 values were normal, several attempts were made to reduce thyroxine substitution. This repeatedly resulted in a significant increase in TSH values, confirming the diagnosis of mild congenital primary hypothyroidism. The presence of maternal antithyroid antibodies was excluded and normal orthotopic thyroid tissue was demonstrated by ultrasound.

Chest radiographs showed diffuse ground glass opacity increasing from days 3 to 13 of life (figure 1A). Oxygen supplementation was initiated. At 14 days, the infant was intubated electively for 

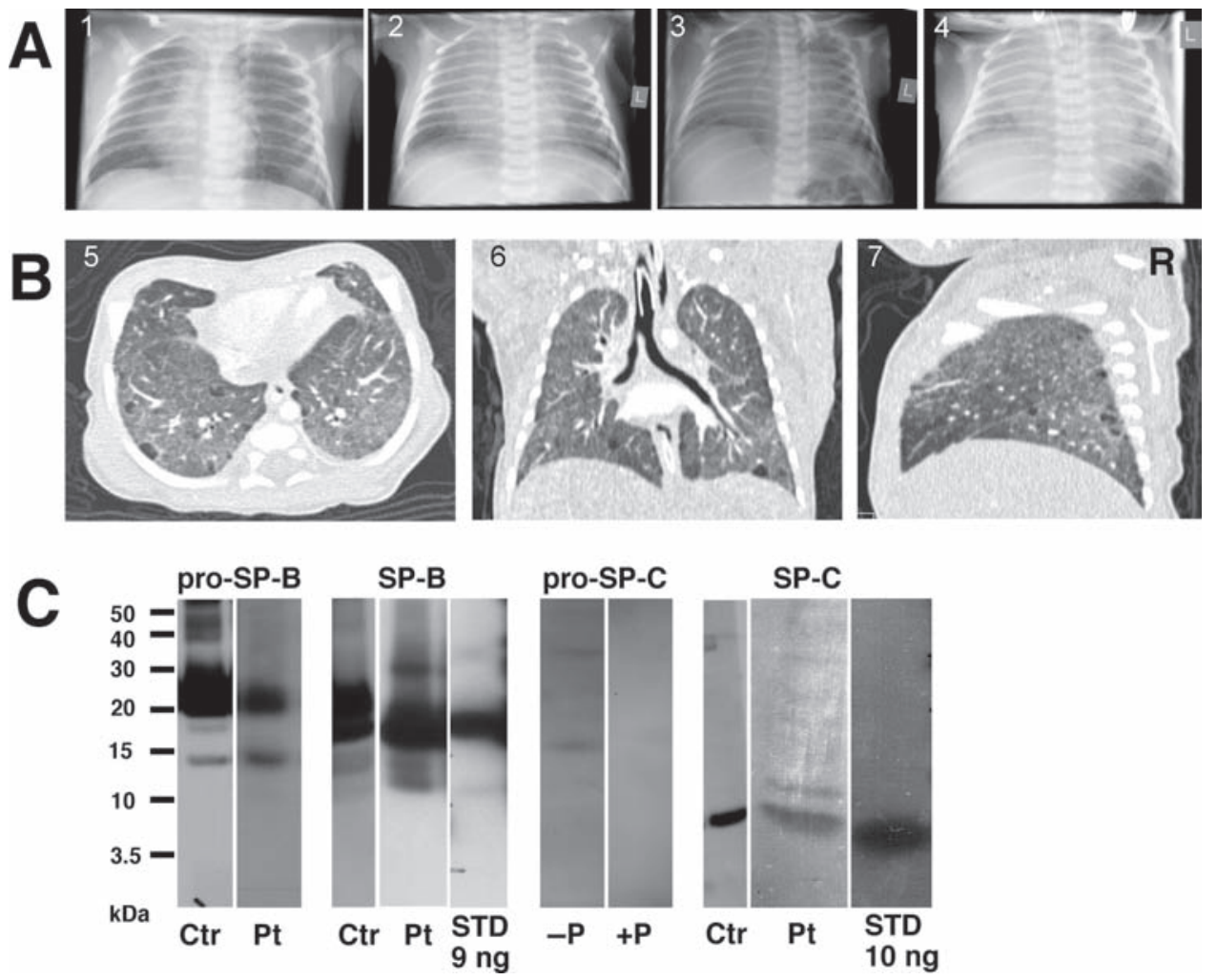

Figure 1 Chest radiographs of the patient, CT scan and bronchoalveolar lavage fluid immunoblot analysis. (A) Chest radiographs taken at days of life 3 (1), 8 (2), 13 (3) and 14 (4; after endotracheal intubation) demonstrate continuous deterioration, diffusely reduced gas entry and increasing fluid content of the lung as well as the gradual development of localised trapped air (bullae). (B) CT scan on day 14 of life. Solidified lung tissue; inhomogeneous gas distribution and subpleural bullae. 5, Transversal view; 6 and 7, frontal and sagittal (right hemithoracic) reconstruction. Both conventional and CT studies are consistent with the most severe interstitial lung disease. (C) Immunoblot analysis of bronchoalveolar lavage material (10 $\mu \mathrm{g}$ of total protein per lane) at 7 months of age. Ctr, control; Pt, patient; Pro-surfactant protein B (SP-B) 21 and $14 \mathrm{kDa}$. Mature SP-B was detected in normal amounts (compared to standard (STD) of $9 \mathrm{ng}$ SP-B). An aberrant proform of SP-C was detected at about $15 \mathrm{kDa}$ in small amounts only in the patient (control not shown). This band was specifically displaced by competing SP-C peptide added in excess (+P). Mature $\mathrm{SP}-\mathrm{C}$ was detected in small amounts only, running mostly as monomers but some as dimers (compared to standard of $10 \mathrm{ng}$ ). The reduction in $\mathrm{SP}-\mathrm{C}$ was reproducible in two other lavage samples from different time points.

a CT study of the thorax (figure 1B). High oxygen concentration and high inspiratory pressure were needed while on mechanical ventilation. Intratracheal surfactant administration (poractant $\alpha$ $100 \mathrm{mg} / \mathrm{kg}$ ) immediately improved oxygenation, but repeated administrations had no sustained effect. Extubation 2 days later failed within $48 \mathrm{~h}$ because of respiratory exhaustion. Due to a 'white lung' on chest radiographs and emphysematous bullae, high frequency oscillatory ventilation (HFOV) was initiated. Diuretics, corticosteroid treatment, inhaled nitric oxide and hydroxychloroquine had no satisfactory effect. Oxygen demand remained at $50-80 \%$. From 9 weeks of life, the infant was ventilated via a tracheal cannula. Parental consent to perform an open lung biopsy was denied. After 4 months, weaning from HFOV to conventional ventilation was possible. At 6 months, an MRI scan of the brain showed no abnormality. A severe increase in pulmonary vascular resistance developed gradually and was treated with sildenafil, bosentan and amlodipin with no apparent effect. In response to the parents' strong wish, the patient was discharged on intense home ventilation despite a poor prognosis. $\mathrm{He}$ died soon thereafter at 10 months of age from respiratory and right heart failure. A postmortem was declined by the parents.

\section{DNA analyses}

After written informed consent, genomic DNA was prepared from peripheral blood leucocytes of the patient and both parents using standard procedures. Sequencing of the entire coding regions and exon-flanking intronic sequences of the SFTPB, SFTPC and ABCA3 genes (including immediate promoter regions of $S F T P B$ and $S F T P C$ ) was performed as previously reported ${ }^{11}$ using the ABI PRISM Dye Terminator Cycle Sequencing Ready Reaction kit (Applied Biosystems, Darmstadt, Germany) and an ABI 310 or ABI 3130xl Genetic Analyzer.

\section{Biochemical analyses}

Bronchoalveolar lavages $(4 \times 1 \mathrm{ml} / \mathrm{kg}$ body weight of normal saline) were centrifuged to remove cells and supernatants were analysed for total protein content with the Bio-Rad Protein Assay kit (Bio-Rad, Richmond, California, USA). Then, $10 \mu \mathrm{g}$ of total protein were separated under non-reducing conditions on NuPage $10 \%$ Bis-Tris gels with the help of a NOVEX X-cell II Mini-Cell system (Novex, San Diego, California, USA). SPs and their proforms were detected with polyclonal rabbit antisera, as described previously. ${ }^{12}$ Lipid classes and molecular species were determined by electrospray ionisation tandem mass spectrometry analysis as described previously..$^{13}$ Control bronchoalveolar lavage specimens were obtained under previous protocols. ${ }^{14}$ Briefly, the samples were from a newborn aged 4 weeks, two 4 - and 14-month-old infants (all three with 
the diagnosis of bronchitis and absence of parenchymal lung disease) and a 40-year-old adult (healthy control).

\section{RESULTS \\ DNA analyses}

Since the clinical picture was consistent with a congenital disturbance of the pulmonary surfactant system, the SFTPB and $S F T P C$ genes were initially sequenced. No abnormality was detected in SFTPC, while in SFTPB a frequent polymorphism, a $G \rightarrow A$ exchange at 384 base pairs upstream of the transcriptional start site, in a TTF-1 binding site was present in the heterozygous state. This polymorphism is associated with reduced transcriptional activity of the SFTPB gene. ${ }^{15} A B C A 3$ sequencing did not reveal a relevant alteration. Sequencing of the NKX2-1 gene led to the detection of a novel heterozygous 29 -base pair deletion (c.278_308del) in exon 2 resulting in a frameshift starting at amino acid position 93 and in a premature stop codon (p.Ala93GlyfsX54) rendering the protein non-functional. This mutation was not detectable in leucocyte DNA from the parents.

\section{Biochemical and lipid analyses}

At a protein level, serial analyses of bronchoalveolar lavage specimens from postnatal days 14, 98 and 208 demonstrated a consistent reduction in mature SP-C and some aberrantly processed pro-SP-C, while mature SP-B was present in normal amounts (figure 1C). The percentage of surface-active phospholipids phosphatidylcholine and phosphatidylglycerol was severely reduced, as was dipalmitoyl-phosphatidylcholine, demonstrating perturbed surfactant phospholipids homeostasis (table 1).

\section{DISCUSSION}

Although several heterozygous mutations (including null alleles) have been reported, there is only a single report describing fatal neonatal respiratory failure due to a NKX2-1 defect. ${ }^{10}$ Interestingly, the phenotype with respect to the grade of hypothyroidism at birth and the finding of normal thyroid tissue was identical to ours and not among the most

Table 1 Mass spectrometry phospholipid analysis of pulmonary surfactant material recovered by bronchoalveolar lavage

\begin{tabular}{lcr}
\hline & $\begin{array}{l}\text { Mean of } 4 \\
\text { different } \\
\text { controls }\end{array}$ & $\begin{array}{l}\text { Case at 3 } \\
\text { different } \\
\text { time points }\end{array}$ \\
\hline Phosphatidylcholine (\% total PL) & $73.2 \pm 5.2$ & $53.5 \pm 3.4^{*}$ \\
Dipalmitoyl-PC (PC 32:0) (\% of total PC) & $50.4 \pm 2.5$ & $29.9 \pm 3.6^{*}$ \\
Phosphatidylglycerol (\% total PL) & $1.3 \pm 0.3$ & $0.5 \pm 0.1^{*}$ \\
Lyso-PC (\% total PL) & $9.9 \pm 3.0$ & $2.1 \pm 1.0$ \\
Phosphatidylethanolamine (\% total PL) & $1.7 \pm 0.4$ & $4.7 \pm 0.3$ \\
Plasmalogens (\% total PL) & $4.6 \pm 1.7$ & $17.6 \pm 1.5$ \\
Phosphatidylserine (\% total PL) & $4.8 \pm 1.7$ & $12.4 \pm 1.2$ \\
Sphingomyelin (\% total PL) & $4.3 \pm 1.9$ & $6.8 \pm 0.8$ \\
\hline
\end{tabular}

\footnotetext{
Patient samples were taken on postnatal days 14,98 and 208, at least 2 weeks after surfactant replacement. PL composition in the patient was stable over time. For comparison, lavage material from controls was analysed in parallel. The relative abundance of the typical surfactant $\mathrm{PL}$ classes (PC, PG) and of the molecular species PC 32:0 (in \% of total PC) were compared by $t$ test. The surfactant-specific species were significantly reduced in the case $\left({ }^{*} p<0.05\right)$ such that the relative amounts of membrane PLs (phosphatidylethanolamine, plasmalogens, phosphatidylserine and sphingomyelin) were increased. PC, Phosphatidylcholine; PL, phospholipids.
}

severe thyroidal phenotypes observed in carriers of NKX2-1 mutations. Due to the location of the resulting frameshift on the amino terminal side of the conserved domains (homeodomain and 'NKX2-1-specific domain'), there is no doubt about the disruptive nature of the mutation in our case. As speculated by Maquet and colleagues, ${ }^{10}$ a missense mutation, in contrast, may potentially lead to a dominant-negative effect, for example, through DNA binding in competition with the wildtype protein, due to its inability to properly transactivate. This pathophysiological mechanism can be excluded here.

From a clinical standpoint, the nature of the lung disease was a failure of the pulmonary surfactant system. While the reduced amount of mature SP-C and abundance of its precursors in bronchoalveolar lavage may indicate a disturbance of pulmonary surfactant homeostasis, it may not be as good an explanation for respiratory failure as the reduction in surfaceactive phospholipid species observed. While this manuscript was being reviewed, Guillot and colleagues ${ }^{16}$ demonstrated that mutations in NKX2-1, whether associated with a loss or a gain of function, may lead to severe lung disease in early life. In a patient with a loss-of-function mutation, they found a reduction in mature SP-B and SP-C while precursors were abundant.

TTF-1 is known to regulate SFTPC transcription directly ${ }^{17}$ or via an interaction with TAZ (transcriptional co-activator with PDZ-binding motif ${ }^{18}$ ). Since TTF-1 also activates transcription of the $A B C A 3$ gene, ${ }^{19}$ which encodes a lamellar body membrane protein involved in the import of surfactant phospholipids, predominantly phosphatidylcholine and phosphatidylglycerol, it is conceivable that its downregulation results in abnormal pulmonary surfactant lipid composition as shown here. Furthermore, TTF-1 is known to regulate SFTPB transcription. ${ }^{20}$ One may speculate that the additional finding of an $S F T P B$ promoter polymorphism known to be associated with decreased transcription ${ }^{1521}$ is to blame for the severe phenotype. Analyses of bronchoalveolar lavages, however, did not indicate a lack of SP-B.

The question is open, however, why in some cases of NKX2-1 mutations lung disease is absent, transient or mild, while irreversible lung failure from birth is seen in others. Coexisting alterations in other genes (such as the WWTR1 gene encoding $T A Z$, or others) may be involved. Since postmortem morphological analyses of the lung were declined by the parents, it cannot be ruled out that the lack of SP-C and surfactant phospholipids was combined with a structural problem in the lung (branching defect) leading to a reduced number of alveoli and consequent impairment of gas exchange as reported by Maquet and colleagues. ${ }^{10}$

We conclude that irreversible lung failure at birth belongs to the clinical spectrum of heterozygous $N K X 2-1$ gene defects. We show that a NKX2-1 defect disrupts pulmonary surfactant homeostasis at the level of surfactant-associated proteins and phospholipids. When investigating possible causes of this clinical presentation, NKX2-1 defects therefore need to be considered and family history should be examined for symptoms of brain-thyroid-lung syndrome.

Funding This work was supported by a grant from the Bundesministerium für Bildung und Forschung (GOLD.net).

Competing interests None.

Patient consent Parental consent obtained.

Provenance and peer review Not commissioned; externally peer reviewed. 
Contributors BK and MG have contributed equally and are to be regarded co-first authors.

\section{REFERENCES}

1. Nogee LM, de Mello DE, Dehner LP, et al. Brief report: deficiency of pulmonary surfactant protein B in congenital alveolar proteinosis. N Eng/ J Med 1993;328:406-10.

2. Nogee LM, Dunbar AE 3rd, Wert SE, et al. A mutation in the surfactant protein $\mathrm{C}$ gene associated with familial interstitial lung disease. N Engl J Med 2001;344:573-9.

3. Shulenin $\mathbf{S}$, Nogee LM, Annilo T, et al. ABCA3 gene mutations in newborns with fatal surfactant deficiency. N Engl J Med 2004;350:1296-303.

4. Kimura S, Hara Y, Pineau T, et al. The T/ebp null mouse: thyroid-specific enhancer-binding protein is essential for the organogenesis of the thyroid, lung, ventral forebrain, and pituitary. Genes Dev 1996;10:60-9.

5. Devriendt K, Vanhole C, Matthijs G, et al. Deletion of thyroid transcription factor-1 gene in an infant with neonatal thyroid dysfunction and respiratory failure. N Engl J Med 1998;338:1317-18.

6. Pohlenz J, Dumitrescu A, Zundel D, et al. Partial deficiency of thyroid transcription factor 1 produces predominantly neurological defects in humans and mice. J Clin Invest 2002;109:469-73.

7. Krude H, Schütz B, Biebermann H, et al. Choreoathetosis, hypothyroidism, and pulmonary alterations due to human NKX2-1 haploinsufficiency. J Clin Invest 2002;109:475-80.

8. Willemsen MA, Breedveld GJ, Wouda S, et al. Brain-Thyroid-Lung syndrome: a patient with a severe multi-system disorder due to a de novo mutation in the thyroid transcription factor 1 gene. Eur J Pediatr 2005;164:28-30.

9. Carré A, Szinnai G, Castanet M, et al. Five new TTF1/NKX2.1 mutations in brainlung-thyroid syndrome: rescue by PAX8 synergism in one case. Hum Mol Genet 2009;18:2266-76.

10. Maquet E, Costagliola S, Parma J, et al. Lethal respiratory failure and mild primary hypothyroidism in a term girl with a de novo heterozygous mutation in the TITF1/NKX2.1 gene. J Clin Endocrinol Metab 2009;94:197-203.
11. Brasch F, Schimanski S, Mühlfeld C, et al. Alteration of the pulmonary surfactant system in full-term infants with hereditary ABCA3 deficiency. Am J Respir Crit Care Med 2006;174:571-80.

12. Griese M, Schumacher S, Tredano M, et al. Expression profiles of hydrophobic surfactant proteins in children with diffuse chronic lung disease. Respir Res 2005;6:80.

13. Liebisch G, Lieser B, Rathenberg J, et al. High-throughput quantification of phosphatidylcholine and sphingomyelin by electrospray ionization tandem mass spectrometry coupled with isotope correction algorithm. Biochim Biophys Acta 2004;1686:108-17

14. Tafel 0, Latzin P, Paul K, et al. Surfactant proteins SP-B and SP-C and their precursors in bronchoalveolar lavages from children with acute and chronic inflammatory airway disease. BMC Pulm Med 2008;8:6.

15. Thomas KH, Meyn P, Suttorp N. Single nucleotide polymorphism in $5^{\prime}$-flanking region reduces transcription of surfactant protein $\mathrm{B}$ gene in $\mathrm{H} 441$ cells. Am J Physiol Lung Cell Mol Physiol 2006;291:L386-90.

16. Guillot L, Carré A, Szinnai G, et al. NKX2-1 mutations leading to surfactant protein promoter dysregulation cause interstitial lung disease in "Brain-LungThyroid Syndrome". Hum Mutat 2010;31:E1146-62.

17. Kelly SE, Bachurski CJ, Burhans MS, et al. Transcription of the lung-specific surfactant protein $\mathrm{C}$ gene is mediated by thyroid transcription factor 1. J Biol Chem 1996;271:6881-8.

18. Park KS, Whitsett JA, Di Palma T, et al. TAZ interacts with TTF-1 and regulates expression of surfactant protein-C. J Biol Chem 2004;279:17384-90.

19. Besnard V, Xu Y, Whitsett JA. Sterol response element binding protein and thyroid transcription factor-1 (Nkx2.1) regulate Abca3 gene expression. Am J Physiol Lung Cell Mol Physiol 2007;293:L1395-405.

20. Bohinski RJ, Di Lauro R, Whitsett JA. The lung-specific surfactant protein $B$ gene promoter is a target for thyroid transcription factor 1 and hepatocyte nuclea factor 3, indicating common factors for organ-specific gene expression along the foregut axis. Mol Cell Biol 1994;14:5671-81.

21. Foreman MG, DeMeo DL, Hersh CP, et al. Polymorphic variation in surfactant protein B is associated with COPD exacerbations. Eur Respir $J$ 2008;32:938-44. 


\section{Fatal neonatal respiratory failure in an infant} with congenital hypothyroidism due to haploinsufficiency of the NKX2-1 gene: alteration of pulmonary surfactant homeostasis

Barbara Kleinlein, Matthias Griese, Gerhard Liebisch, Heiko Krude, Peter Lohse, Charalampos Aslanidis, Gerd Schmitz, Jochen Peters and Andreas Holzinger

Arch Dis Child Fetal Neonatal Ed 2011 96: F453-F456 originally published online June 28, 2010 doi: 10.1136/adc.2009.180448

Updated information and services can be found at: http://fn.bmj.com/content/96/6/F453

\section{These include:}

References This article cites 21 articles, 8 of which you can access for free at: http://fn.bmj.com/content/96/6/F453\#BIBL

Email alerting Receive free email alerts when new articles cite this article. Sign up in the service box at the top right corner of the online article.

Topic Articles on similar topics can be found in the following collections Collections

Thyroid disease (23)

Genetic screening / counselling (11)

Drugs: respiratory system (8)

Molecular genetics (29)

\section{Notes}

To request permissions go to:

http://group.bmj.com/group/rights-licensing/permissions

To order reprints go to:

http://journals.bmj.com/cgi/reprintform

To subscribe to BMJ go to:

http://group.bmj.com/subscribe/ 